\title{
Racionalidades punitivas. Una epistemología para la objetivación y la historicidad de las políticas del castigo*
}

\author{
Mario Domínguez Sánchez-Pinilla \\ David J. Domínguez González \\ Universidad Complutense de Madrid \\ mariodos@cps.ucm.es \\ dadomi01@ucm.es
}

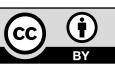

Fecha de recepción: 13-5-2021

Fecha de aceptación: 1-9-2021

\section{Resumen}

La idea de racionalidad en Michel Foucault no se refiere a un criterio de razón universal a modo de conocimiento puro y neutral, sino conjugada en plural como «racionalidades». Funciona como un régimen de verdad que no solo produce nuevos conceptos y una organización histórica de la observación, sino dominios de regulación e intervenciones políticas y técnicas. Aplicadas a la economía punitiva, y por extensión a la del poder, las racionalidades punitivas han permitido aflorar un análisis crítico inusual de los sistemas del castigo mediante diferentes conceptos en apariencia usuales que alcanzan una radicalidad inusitada en la objetivación de las redes de poder/saber, desbordando tanto el campo de la política penal como el de las rígidas explicaciones materialistas. Y en última instancia han permitido construir un orden punitivo macrosocial y unas macroformas de dominación a partir de la diversidad de micropoderes.

Palabras clave: racionalidad punitiva; Michel Foucault; objetos de conocimiento; norma y ley; estrategia; castigo del cuerpo Abstract. Punitive rationalities. An epistemology for the objectification and historicity of
punishment policies

Michel Foucault's idea of rationality does not refer to a universal criterion of reason as pure and neutral knowledge, but rather is understood in the plural, as «rationalities». His perspective functions as a regime of truth that not only produces new concepts and a historical organisation of observation, but also areas of regulation and political and technical intervention. Applied to the punitive economy, and by extension to the economy of power, punitive rationalities have enabled an unusual critical analysis of punishment systems to flourish. This analysis is produced through different concepts, apparently usual, that reach an unusual radicality in the objectification of the networks of power/knowledge that spread beyond both

* Este artículo forma parte del proyecto I+D+I del Ministerio de Ciencia e Innovación «La contemporaneidad clásica y su dislocación: de Weber a Foucault» (PID2020-113413RB-C31). 
the field of penal policy and that of rigid materialist explanations. And ultimately it has allowed a macro-social punitive order and macro-forms of domination to be constructed out of the diversity of micropower.

Keywords: punitive rationality; Foucault; objects of knowledge; norm and law; strategy; punishment of the body

\section{Sumario}

\section{Introducción}

2. Racionalización no, racionalidades

3. Problematización de los objetos del conocimiento: el descubrimiento del cuerpo como objetivo del poder y del saber

4. Norma y conflicto
5. Gubernamentalidad: hacia la creación de un nuevo cuerpo social

6. La evolución de los sistemas punitivos y su carácter estratégico

7. Conclusión

Referencias bibliográficas

\section{Introducción}

El estudio aborda mayoritariamente aspectos de carácter epistemológico y apenas utiliza detalles significativos que sirvan de ejemplificación. Incide ante todo en cómo la reflexión de Michel Foucault en torno a la prisión excede ese ámbito por cuanto proporciona un modo de hacer y un arsenal de conceptos que irán decantándose en trabajos posteriores no solo en los relativos al ámbito punitivo, sino en aquellos dedicados al análisis del poder gubernamental, pese a que siempre evitó dar cuenta de algo así como una teoría del Estado. Entre estos conceptos sociohistóricos que han permitido explorar diferentes ámbitos disciplinarios y a muy distintos niveles (discursivos, éticos, políticos), hemos destacado una secuencia aplicada inicialmente a los aspectos punitivos, aspecto que nos sirven a modo de prueba del alcance de aquellos. No cabe pues buscar en el artículo un mapa comparativo con otros estudios sobre penalidad de cara a ponderar las aportaciones de la contribución del filósofo a la renovación de la historiografía crítica de las racionalidades penales, porque el criterio es otro: el alcance cognoscitivo de la terminología foucaultiana tomando como referencia el ámbito de lo punitivo.

El primer abordaje resalta la noción plural de las racionalidades al criterio weberiano de una racionalidad unificada y coherente a modo de rodillo teleológico aplicable a todo proceso social. Frente a una razón trascendental, las racionalidades punitivas en este caso, al hablarnos de las prácticas, la sistematización y la «racionalización» de una pragmática de la disposición ${ }^{1}$, permiten analizar condiciones de existencia específicas y analizables en el ámbito del

1. Este término está relacionado con la noción de episteme en tanto que orden específico del saber, es decir, de «la configuración, la disposición que adopta el saber en una determinada época y que le confiere una positividad en cuanto saber» (Machado, 1999: 25). 
castigo, lo que impide aseverar una trayectoria lineal y autocentrada en la mejora de los derechos humanos.

En segundo lugar, esta historia crítica de la racionalidad logra una problematización inusitada de los objetos de investigación. En nuestro caso, al apostar por una coherencia intrínseca entre prácticas penales y políticas socioeconómicas, se destaca el descubrimiento del cuerpo como objetivo del poder y del saber, y con ello la caracterización de la máquina disciplinaria cuyo objetivo era vencer la resistencia de la fuerza de trabajo, cubrir sus déficits, imponer su cooperación con el sistema de producción y promover el autocontrol. Así la disciplina carcelaria completa la «subjetivación» del ciudadano y permite un logro considerable cual es el de conciliar la historia del derecho penal y la historia de las ciencias humanas.

En tercer lugar, el estudio de las racionalidades punitivas permite aflorar la disputa compleja entre ley y norma que reside en un desplazamiento en la consideración de esta última como concepto propiamente político, lo cual se halla en consonancia con la concepción que Foucault tiene sobre la política como conflicto, entre lo normal y lo patológico, entre lo normal y lo anormal. Con ello se delinea la posibilidad de un análisis histórico social de los sistemas punitivos capaz de desvelar el carácter ideológico de las legitimaciones que de vez en cuando se invocan desde una perspectiva institucional para imponer nuevos sistemas represivos del conflicto social y nuevos mecanismos de preservación de la hegemonía.

Y por último, la introducción tardía del carácter estratégico, aplicado a las relaciones de poder en tanto en cuanto interconexión de lo múltiple y lo disperso en una forma más o menos coherente y unitaria permite reintegrar lo macro y lo micro del «diseño general» del Estado en el ámbito penitenciario sobre el que bien puede operar la estructura de clases. Todo un ejemplo de cómo el poder, partiendo de lo disciplinario para llegar a las nociones biopolíticas de la gubernamentalidad, resulta a la vez intencional y no subjetivo, es decir, que, si bien tales estrategias globales son irreductibles a los deseos, intereses o voluntades de un grupo social o un individuo en particular, sin embargo, se articulan en torno a un nivel mínimo de racionalidad y cálculo, nivel que posee además formas históricas definidas abiertas a la investigación histórica y social.

\section{Racionalización no, racionalidades}

En el conjunto de la reflexión foucaultiana sobre las formas punitivas, el análisis de las tácticas penales ocupa un lugar destacado. Gracias a ellas, el autor accede a un ámbito de relaciones que no aparece ni en los discursos morales ni en las justificaciones jurídicas que las instituciones penitenciarias dan de sí mismas y de los castigos. Excluir, indemnizar, marcar, encerrar son solo algunos ejemplos que caracterizan eso que Foucault (2018: 21-28) llamó tácticas penales. Pero si insiste en ellas, especialmente en el encierro, no es, como se sabe, para tratar de reconstruir las representaciones mentales que justifican esas 
prácticas penales, sino para analizar qué formas de poder son puestas en juego «para que a las infracciones que ponen en tela de juicio sus leyes, (...) se responda por tácticas como la exclusión, la marca, la indemnización o el encierro» (ibid: 29). En primer lugar, en Foucault existe por lo tanto una historia crítica de la racionalidad que es la historia de la transformación de las racionalidades y no la historia del acto fundador mediante el cual la razón habría sido descubierta en su esencia: diferentes instauraciones, diversas creaciones, variadas modificaciones por las cuales las racionalidades se engendran unas a otras, se oponen unas a otras, se excluyen entre sí, y cómo los objetos que designa se constituyeron de modo inmanente a la formación de dicha racionalidad, al inscribirse estratégicamente en «lo real». En segundo lugar, al atravesar los supuestos de las tradiciones teóricas sociales centradas en el sujeto, la obra de Foucault sitúa la racionalidad no tanto en los atributos del actor o en las características de la acción, sino en las condiciones discursivas y prácticas de la acción, que denomina de diversas maneras a lo largo de su obra («formaciones discursivas», "regímenes de verdad», «juegos de verdad», relaciones «saberpoder»). Así que, si queremos mantener este término tan cercano a Weber de racionalización, no puede entenderse como un concepto unificado por referencia a un tipo de acción social (como la acción intencional-racional o la acción comunicativa); tampoco puede entenderse como un proceso unificado coherente en todas las facetas e instancias específicas de la racionalización. De ello, el autor francés deduce que no es un concepto útil para caracterizar los procesos históricos en términos de aumento o disminución de la racionalidad, más bien lo que surge es una comprensión de los sistemas de racionalidad plurales, no unificados y que carecen de una coherencia necesaria entre sí, pero que, no obstante, poseen condiciones de existencia específicas y analizables. Esto, y no las teleologías del sujeto racional o de la racionalización, es lo que proporciona el terreno de una historia crítica de la racionalidad.

En este sentido, el análisis de las racionalidades punitivas no solo se concentra en los mecanismos de legitimación del arte de castigar, la dominación o el enmascaramiento de la violencia, sino que se centra en el conocimiento que forma parte de las prácticas, la sistematización y la «racionalización» de una pragmática de la disposición. Es decir, la racionalidad no se refiere a una razón trascendental, sino a las prácticas históricas; no implica un juicio normativo, ya que se refiere a las relaciones sociales. Foucault (1991: 79) deja muy claro este punto cuando insiste en el significado relativo e instrumental de la racionalidad, de modo que si hablamos de la irracionalidad de la tortura pública tengamos en cuenta que no lo es ni más ni menos que la cárcel, pero sí lo es en términos relativos respecto a una práctica punitiva que supone el cálculo de la utilidad o la justificación de la pena.

En esta dirección, hablar de racionalidades no implica reconocer un conocimiento puro y neutral que simplemente «representa» la realidad tutelada. No es una instancia exterior, sino un elemento del propio gobierno que ayuda a crear un campo discursivo en el que el ejercicio del poder de castigar y prevenir es «racional». Sugiere por tanto que es importante ver no solo si la racio- 
nalidad de un tipo es una representación adecuada de la sociedad, sino también cómo funciona como una "política de la verdad», produciendo nuevas formas de conocimiento, inventando diferentes nociones y conceptos que contribuyen al "gobierno» de nuevos dominios de regulación e intervención.

La búsqueda de Foucault se dirige hacia las condiciones de existencia de los discursos, de esos juegos de la verdad en los que el poder atraviesa el campo del saber y de esta forma consigue reclamar la incitación, la multiplicación de los discursos, de lo que "puede ser dicho", y a la vez permitir su supresión o censura de lo que «jamás puede ser dicho». Estos imperativos del poder y del conocimiento son componentes de un mismo proceso que se aplica en cada ocasión con una táctica estratégica diferente: es el «pensamiento como estrategia", como poder. Además, al proceder de este modo, se adopta la perspectiva a largo plazo propia de Foucault, una perspectiva que advierte de la tentación de identificar en los procesos históricos solo elementos de continuidad o únicamente elementos de discontinuidad. Por ejemplo, el período actual, en términos punitivos, no marca una ruptura o el comienzo de una era totalmente nueva, así como no representa con seguridad la culminación, el punto último, la meta preestablecida de una etapa anterior. Por el contrario, es el resultado de una estratificación de procesos, prácticas, principios y discursos que se rearticulan en el presente, según una fórmula nueva y original, pero que ciertamente no pierden el hilo que los conecta con el pasado: pensar la discontinuidad, para privilegiar los acontecimientos, su irrupción y las posibilidades ${ }^{2}$.

El giro, por tanto, es notable: en lugar de abordar las tácticas punitivas al estilo tradicional, como un instrumento o una consecuencia de las reglas del derecho, Foucault opta por insertar estas tácticas en el marco de una historia política de los cuerpos. El objetivo consiste así en ver cómo a través de las tácticas penales (el encierro, sobre todo) se pueden objetivar las diferentes relaciones de poder (soberanía, disciplina) que se incardinan en los cuerpos, para cercarlos, marcarlos, domarlos, someterlos a suplicios, forzarlos a trabajar, obligarles a ceremonias, o exigir de ellos unos signos (Foucault, 1975a: 32). En este sentido, el castigo es algo que involucra cuestiones de poder y de gobierno, pero también formas de conocimiento que se forman y se entrelazan con la práctica del poder de castigar. De esta intersección, es testigo el complejo penal moderno: lejos de centrarse en el delito, su interés se centra en la figura del delincuente. Para lo cual, la operación penal se carga de estimaciones y de personajes extrajurídicos, tanto por lo que respecta al procedimiento penal como en lo que se refiere a la ejecución propiamente dicha de la pena.

Este esfuerzo por conciliar historia del derecho penal e historia de las ciencias humanas es quizá uno de los aspectos más originales de su análisis sobre la práctica del encierro (Garland, 1990: 162). Y es también lo que permite al

2. En La arqueología del saber propone que los diversos análisis de los objetos de investigación no pueden tener capacidad explicativa a través de la tradición o el fundamento, sino que debemos basarnos en las «transformaciones que valen, como fundación y renovación de las fundaciones» (Foucault, 1969: 7). 
propio Foucault desbordar el campo de la política penal y situar su indagación histórica en el estudio de las racionalidades punitivas, entendiendo por esto no la historia de la institución penitenciaria en sentido estricto ${ }^{3}$, sino el análisis de las tácticas y de las estrategias penales que subyacen, desde finales del siglo XVIII, a la extensión de los mecanismos científico-disciplinarios de formación de la individualidad. Por supuesto, estas racionalidades punitivas no son objetos directamente aprehensibles en los códigos jurídicos; son entidades teóricas fruto de la reelaboración conceptual que Foucault hace de una gran diversidad de materiales de archivo: reglamentos de prisión, de escuelas, de fábricas, legislaciones penales, informes sobre inspecciones carcelarias, ordenanzas militares, peritajes psiquiátricos, archivos parlamentarios, etcétera. Ninguno de estos materiales por sí solo ofrece información explícita acerca del cómo y el porqué de las racionalidades punitivas. Es Foucault quien instala, con sus preguntas y sus herramientas metodológicas, un modelo de análisis que construye una organización nueva de la observación histórica, por cuanto produce informaciones ("poder de normalización», "poder disciplinario», "complejo poder-saber", etcétera) que no podrían «observarse» sin el horizonte de inteligibilidad engendrado por las teorías ${ }^{4}$. Si existen, es porque son planos de realidad accesibles a través de las fuentes, pero también constituyen el resultado de una operación teórica que construye sus objetos por medio de la reorganización conceptual de los enunciados de base, traduciendo el contenido explícito de las fuentes en datos que construyen una problemática que no estaba presente en los enunciados descriptivos de los materiales. Así, al hablar de reglamentos de fábrica, de ordenanzas militares, de inspecciones carcelarias, de instrucciones escolares, de peritajes psiquiátricos o acondicionamientos espaciales, Foucault no ve solamente una serie de proposiciones referidas a dominios aislados, sino un objeto de análisis construido a partir del supuesto de que tales dominios están atravesados por formas similares de racionalidad. Esto permite sospechar que las diferentes normatividades se hacen conmensurables en un mismo tipo de cálculo, como si el carácter transferible de las técnicas disciplinarias permitiera la síntesis y las transacciones entre los

3. Así, aunque Vigilar y castigar (1975a) lleve por subtítulo Nacimiento de la prisión, el libro funciona menos como una historia de la prisión que como un estudio sobre sus condiciones de posibilidad. De ahí el lugar, absolutamente central, que ocupa el capítulo dedicado a las "disciplinas». Según Foucault, para que la prisión pueda monopolizar el territorio penal, fue necesaria la generalización de las técnicas disciplinarias. Solo una sociedad que conoce la difusión de la disciplina, que ve cómo sus técnicas de control se «desinstitucionalizan" y tienden a funcionar como procedimientos transferibles y adaptables a otras instituciones, está en posición de incorporar la pena de prisión como parte funcional de la totalidad social y económica del sistema. Véase Foucault (1973: 137; 1975b: 728), Ewald (1990: 164-169), Lascoumes (2007: 19), Boullant (2003: 82), Garland (1990: 163-164). No estaría de más señalar que su libro fundamental al respecto, Vigilar y castigar, llega en su indagación hasta 1840 como ha insistido en más de una ocasión, de ahí lo gratuito de muchas imputaciones infundadas. Véase por ejemplo la entrevista que sostienen con él en 1981 Christian Panier y Pierre Watte (2012).

4. Véanse, al respecto, las interesantes reflexiones epistemológicas de Passeron (1991: 334-348). 
diferentes espacios sobre los cuales actúan dispositivos de poder dispares, como la familia, el sistema judicial, el asilo psiquiátrico, el aparato penitenciario o el complejo tutelar ${ }^{5}$.

Puesto que Foucault lleva a cabo un análisis de las diferentes formas de racionalización, y de las relaciones diferenciales entre el poder y el conocimiento, no es necesario adoptar una concepción de los potenciales universales y de los intereses emancipadores de los seres humanos que se han visto sofocados o deformados por las formas actuales de racionalización. Más bien el uso del plural de las «racionalidades punitivas» le permite al autor francés hacer críticas de los sistemas penitenciarios desde diversos puntos de vista en su despliegue histórico y práctico, y sin emprender nada tan grandioso como una crítica a la globalidad. De ello se desprende, además, que una posición normativa no tiene por qué formularse en términos de una concepción universal del ser humano, de modo que permite sospechar que existen otras posibilidades y que hay motivos (discutibles) para decidir qué estado de cosas es preferible. En efecto, uno de los aspectos satisfactorios de los análisis foucaultianos es que estos no sienten la necesidad de invocar puntos de vista normativos y visiones políticas estrictas y universales desde las que se puedan juzgar las formas de poder. $\mathrm{Su}$ radicalidad estriba en la capacidad para multiplicar las formas de crítica al tiempo que se abstiene del privilegio del portavoz, y evita el deber sagrado del crítico social para erigirse desde la posición de acceso privilegiado a un conjunto superior de valores. ${ }^{6}$ Con ello se logra evitar, como indica en las primeras páginas de Vigilar y castigar, el hecho de considerar el paso del castigo a la vigilancia sistémica, es decir, del cadalso a la cárcel, a través de un criterio internalista y de carácter triunfalista en la transformación del sistema punitivo occidental en el siglo XIX mediante una creciente humanización de las penas

5. Cuando se habla de «síntesis» y de «transacciones», nos referimos al hecho de que se produzcan intercambios recíprocos entre las diferentes normatividades. Es lo que permite, por ejemplo, que el peritaje del psiquiatra adquiera sentido para un magistrado y, por tanto, pueda transformar el grado de anormalidad de un detenido en un grado de presunción de culpabilidad; es lo que permite asimismo que las informaciones proporcionadas por la encuesta del trabajador social puedan traducirse en medidas impartidas por un tribunal de menores, etcétera. Así, a pesar de las diversas normatividades, el hecho es que la sociedad disciplinaria alienta juicios y apreciaciones comunes. Es una sociedad de comunicación abierta, pues permite que todo se comunique con todo, según un principio de homologías infinitas. Véase Ewald (1990) y, sobre todo, Legrand (2007: 261-269) y Legrand et al. (2003: 29-86).

6. Hay en todo esto una contextualización específica: la reacción de Foucault frente al intelectual orgánico, propio del compromiso humanista y marxista de la época, que experimenta en su persona las contradicciones de la historia para señalar el camino del porvenir. Frente a esa figura reclamará la del intelectual específico, que no disocia la reflexión intelectual de la lucha social, pero no obstante no se erige en representante de nadie, sino que más bien ofrece su especialización conceptual a modo de caja de herramientas y cede su protagonismo de portavoz de la denuncia para que sean los sujetos que viven de cerca esas contradicciones quienes reclamen directamente sus reivindicaciones. Así lo hizo con la creación del Grupo de Información de Prisiones (GIP) a principios de los años setenta, que permitió visualizar lo oculto tras los muros de la censura. 
y sus efectos en el juicio y el castigo. Frente a esa tendencia, introduce en cambio cuatro modos de problematización, que son: el objeto cambiante del castigo; el trabajo cambiante del juicio, la pena y el castigo; el modo versátil de subjetivación de los castigados, y, quizás lo más importante para su investigación, el telos del castigo y su lugar dentro de un esquema o modo de ser más amplio de prácticas y formas de conocimiento relacionadas, esto es, una economía de poder y de saber.

Teniendo en cuenta la forma en que Foucault inscribe una historia crítica de la racionalidad, resulta obvio que se debe restringir el uso de dicho término a un significado instrumental y relativo. Tal es el propósito de este artículo: seguir esa dirección restrictiva en lo relativo al análisis de los sistemas de castigo. De este modo, en vez de evaluar las teorías y prácticas punitivas de las sociedades modernas y contemporáneas sobre la base de un criterio puro y universal de razón, trataremos de examinarlas como prácticas o sistemas de prácticas inscritas en cierto régimen de racionalidad que tendría por tanto un carácter histórico y relativo.

\section{Problematización de los objetos del conocimiento: el descubrimiento inicial del cuerpo como objetivo del poder y del saber}

Un desarrollo interesante a partir de los efectos de la racionalidad punitiva reside en la problematización de los objetos de investigación, lo cual no significa la representación de un objeto preexistente, ni la creación discursiva de un objeto que no existe. Más bien se trata del conjunto de prácticas discursivas y no discursivas que hace que algo entre en el juego de lo verdadero y de lo falso y lo constituye como objeto para el pensamiento (Foucault, 2007b: 371). En otras palabras, se trata de describir y comprender las formas de problematización de los objetos del conocimiento, en este caso de los sistemas punitivos. Tal objetivación del conocimiento se aleja de formas tradicionales de análisis histórico, como la historia de las ideas o las mentalidades, y manifiesta su potencia en la interrogación de su condición singular, específica y local. En cierto modo, tal es la tarea de la investigación, no tanto resolver sino problematizar. La crítica siempre está acompañada por el enunciado que moviliza: crítica de la razón, de la cárcel, de la sociedad, del Estado. La crítica se convierte en una función subordinada que exige una utilidad, que compensa y que generalmente está asociada con la exclusión o la rectificación de errores, posturas o formas de comprender el mundo.

Pues bien, toda esta infraestructura, todo este entramado de prácticas, instituciones y saberes, organizado en torno a la visibilización del cuerpo y la intervención correctiva sobre sus aptitudes, es lo que Foucault llama racionalidades punitivas. La aplicación del enfoque genealógico, a partir de la reflexión foucaultiana, permite identificar las fuerzas que han generado las prácticas actuales en materia penal/socioasistencial e identificar las condiciones históricas y sociales de las que aún dependen. Y nos permite así apostar por una coherencia intrínseca entre prácticas penales y políticas socioeconómicas. La prisión 
correccional y la fábrica taylorista, la filosofía de la reinserción y el desarrollo de la asistencia social, la baja tasa de encarcelamiento y el descenso del desempleo; todas estas características encuentran cierta coherencia dentro de un modelo inclusivo de ciudadanía social basada en el trabajo asalariado.

De ahí el porqué de un concepto como el de racionalidades punitivas. Con él se alude al conjunto de tácticas y de procedimientos prácticos que conforman el dispositivo científico-judicial de la penalidad. La referencia es amplia y alberga formas inéditas de conocimiento y de punición. La más conocida es la práctica del encierro y de la prisión ${ }^{7}$, pero también se pueden incluir las diversas formas de control pospenitenciario y de panoptismo asistencial. En este sentido, la racionalidad punitiva apunta a la materialidad del castigo, a la manera en que este último se ejerce sobre los cuerpos, no a las razones que ofrece de sí mismo para hacerlo. De ahí el interés por los programas de tratamiento (aislamiento celular, trabajo carcelario, control técnico-médico del encierro) y los modelos de acondicionamiento material (panoptismo) —ambos ejemplos representan descripciones minuciosas de cómo opera el poder de castigar sobre los cuerpos-. Así, en el primer caso, se atiende a los efectos que tales programas ejercen sobre la mecánica humana, esto es, a observar el modo en que el cuerpo es sometido a una técnica que hace de sus gestos, de sus movimientos, de su tiempo, una materia sobre la cual operar, a fin de encauzarla y someterla a una serie de hábitos incorporados. En el segundo, el objetivo más bien consiste en saber cómo acondicionar el medio para influir estratégicamente en las conductas, al distribuir a los individuos en un campo permanente y continuo de visibilidad. Y eso no es todo, ya que la aplicación de tales prácticas hace posible el desarrollo de un sistema de documentación permanente (psicológica, criminológica, médica, etcétera) con el que se establecen medias y diferencias entre los individuos (localizar aptitudes, medir progresiones, intervenir regresiones, establecer comparaciones, etcétera). Saber que se convertirá a su vez en un poderoso agente de normalización al revelar como «punibles» los aspectos más ínfimos de las conductas (la duración excesiva de un aprendizaje, el retraso en la realización de un ejercicio, las interrupciones constantes de tareas, la suciedad o la postura incorrecta del cuerpo, las faltas de atención, los descuidos, etcétera).

Como decíamos, las tecnologías disciplinarias constituyen el espacio productivo de un poder cuyo fundamento se encuentra en la economía política,

7. Decimos inéditas porque la sentencia a prisión no fue, hasta finales del siglo XviII, un castigo dentro del sistema penal. Esta sentencia, entendida como una pena consistente en la privación de libertad, prolongada por un periodo de tiempo y sin que vaya acompañada de otro sufrimiento posterior, es reciente. Es cierto que, en la práctica judicial, ya existía algo así como las prisiones, pero el uso que se hacía de ellas era solamente procesal: antes de 1775 la prisión no se utilizaba como pena autónoma y ordinaria, era un lugar (mazmorras en castillos medievales, edificios insalubres) destinado a asegurar la integridad física de los deudores y los delincuentes en espera de juicio, no un proyecto de reforma. Sobre las prisiones procesales, véase Pavarini y Melossi (1977: 19), Ignatieff (1978: 29-31), Foucault (1973: 84). 
y la prisión es una forma institucional de dicho proceso. La gestión institucional de ese espacio permite operar a los principios de diferenciación materializando distinciones y jerarquizando deficiencias, aunque debe admitirse que lo que está en juego es el control de los individuos. Con Foucault, podemos entender cómo una economía política del cuerpo podría emerger de la prisión; de hecho, la invención del sistema penitenciario está inserta en el concepto del cuerpo como una entidad productiva. Si en el trabajo de Ignatieff (1978) se percibe la detención como una «reacción» a la necesidad de un tratamiento eficiente del desorden social, Foucault en cambio describe el nacimiento de la prisión como la transición de un modelo de poder reactivo y de carácter soberano basado en el imperio de la ley y establecido sobre el territorio a uno productivo. Los dispositivos de poder y control disciplinarios necesitaban activarse productivamente porque existía una improductividad social difundida, una dispersión latente de recursos y una falta de cooperación fructífera. Esto es, las relaciones capitalistas de producción necesitaban producir la fuerza de trabajo, prepararla para la cooperación para la que parecía inapropiada, descalificada, insuficientemente socializada y a menudo explícitamente reacia.

Además, solo en este tipo de sociedad capitalista puede ocurrir que la pena se conciba como un castigo privativo de la libertad, por cuanto la privación de la libertad carecía de sentido alguno en sociedades basadas en la esclavitud o en el trabajo servil. Un autor marxista del derecho como Evgeni B. Pashukanis (1927) escribía que, puesto que puede aflorar la idea de la posibilidad de espiar el delito con un quantum de libertad determinado abstractamente, era necesario que todas las formas de riqueza se redujeran a la forma más simple y abstracta del ser humano medido en forma temporal. Una vez se desarrolla el modo de producción capitalista, el trabajador, eliminado el vínculo feudal, llega a ser libre y puede vender temporalmente y de forma voluntaria su propia fuerza de trabajo. También se libera la propiedad de los medios de producción y el resultado es su acumulación en pocas manos. El trabajador debe adecuarse a la necesidad establecida por el nuevo modo de producción, lo cual supone tiempos de trabajo impuestos por el empresario primero, por el mercado laboral abstracto después, a través de la vigilancia y la supervisión. En este periodo histórico que supone el nacimiento de la economía capitalista y de la concepción protestante de la vida y del trabajo, se introduce el valor del concepto de disciplina laboral o religiosa como elemento central del proceso de racionalización de la naciente sociedad capitalista ${ }^{8}$.

8. En cuanto a la disciplina, nos recuerda Foucault en Vigilar y castigar (1975a: 139-174), se trata de una forma de poder que tiene como objetivo los cuerpos en sus detalles, en su organización interna, en la eficacia de sus movimientos. En este sentido, hay que distinguirla de las otras formas de poder que también tienen por objeto el cuerpo: la esclavitud (que establece una relación de propiedad), la domesticación (que se define por la satisfacción del capricho del amo), el vasallaje (una relación codificada entre el señor y los súbditos, pero lejana) y el ascetismo cristiano (marcado por la renuncia, no por el fortalecimiento de las capacidades corporales). La disciplina mantiene con el cuerpo una relación analítica. Según sus términos, nos encontramos con una microfísica del poder, con una anatomía 
Estas formas de poder inscritas en el cuerpo no se manifiestan bajo una violencia física, sino bajo su sujeción en tanto en cuanto objeto de conocimiento. Tales discursos sobre el cuerpo manifestados históricamente han permitido comprender el acceso del cuerpo en el marco político:

El cuerpo está también directamente inmerso en un campo político; las relaciones de poder operan sobre él una presa inmediata; lo cercan, lo marcan, lo doman, lo someten a suplicio, lo fuerzan a unos trabajos, lo obligan a unas ceremonias, exigen de él unos signos. Este cerco político del cuerpo va unido, de acuerdo con unas relaciones complejas y recíprocas, a la utilización económica del cuerpo; el cuerpo, en buena parte, está imbuido de relaciones de poder y de dominación, como fuerza de producción; pero en cambio, su constitución como fuerza de trabajo sólo es posible si se halla prendido en un sistema de sujeción. (...) El cuerpo sólo se convierte en fuerza útil cuando es a la vez cuerpo productivo y cuerpo sometido. (Foucault, 1975a: 32-33)

El control penal funcionó pues como una máquina disciplinaria cuyo objetivo era vencer la resistencia de la fuerza de trabajo, cubrir sus déficits, imponer su cooperación con el sistema de producción y promover el autocontrol. Yendo más allá de Foucault y del marco histórico de Vigilar y castigar, eso supone la inclusión de diversas prácticas para el control y la vigilancia de la población, pero también implica la educación pública, la seguridad social y la salud pública: todas las tecnologías necesarias para garantizar y perpetuar la administración productiva de la población, dentro del marco del Estado de bienestar y la regulación salarial fordista. En otras palabras, se ubica en un período histórico en el que la fuerza de trabajo debía ser disciplinada con el objetivo de insertarla en la organización industrial del trabajo; un sistema caracterizado por el pleno empleo, en el cual el «trabajo asalariado» era un acceso habilitado hacia la ciudadanía social. En ese contexto, la fuerza de trabajo aparecía como insuficiente y descalificada, y necesitaba cierta disciplina fabril para alcanzar el nivel de cooperación y la eficiencia económica requerida por el capitalismo. Aquellos que quedaron fuera tuvieron que ser reintegrados a través del complejo penal correccional (Giorgi, 2007).

Junto a la disciplina fabril, que busca el ensamblaje del conjunto, la «subjetivación» del ciudadano se completa con esta normalización disciplinaria de carácter más individualizante y que se puede aplicar a todas las instituciones sociales análogas a la fábrica (cárceles, workhouses, cuarteles, manicomios, hospitales, escuelas, etcétera) caracterizadas por el modo de construir, aceptar y reproducir la disciplina social requerida. El conjunto ofrece como resultado la creación de un nuevo sujeto capaz de moverse en el interior de la naciente sociedad urbana. Así pues, la función original de la cárcel no se diferencia mucho de la señalada en Vigilar y castigar: un sistema correccional dirigido a la normalización y al disciplinamiento de las masas de desocupados y vaga-

política del cuerpo cuya finalidad es producir cuerpos útiles y dóciles o, si queremos, útiles en la medida de su docilidad. En efecto, el objetivo de la disciplina es aumentar la fuerza económica del cuerpo al mismo tiempo que se reduce su fuerza política. 
bundos. Según el diferente grado de desarrollo económico, asistiremos a una multiplicidad de modalidades punitivas y de instituciones penitenciarias que en cualquier caso ya no se corresponden con el internamiento punitivo difuso y masivo de, por ejemplo, las antiguas workhouses u hospitales generales.

Esta introducción implicará un nuevo modo de registrar, organizar y archivar el cuerpo, ya no solo como unidades generalizadas, sino también como singularidades particulares. De este modo, se hará posible la "caracterización del individuo como individuo y la ordenación de una multiplicidad dada». Lo que se manifiesta mediante los procedimientos del examen es la formación de un espacio de archivo, el funcionamiento como un procedimiento de objetivación y sometimiento. Cabe añadir sobre esta función de los «nuevos archivos» lo que Foucault analiza:

Lo que era innovador sobre los nuevos archivos fue precisamente el hecho de que objetivaban los individuos no como miembros de una categoría preexistente, sino en toda su unicidad y singularidad. Lejos de ser archivados en términos de sus propiedades compartidas, los seres humanos han sido ligados a todas las series únicas de eventos (médicos, militares, educativos, eventos penales) que les han convertido en lo que son en tanto individuos históricos - una historia que podría ahora tomar la forma de un archivo mientras que el individuo se convierte en el caso-. (Landa, 2003: 11)

En otras palabras, la formación del espacio de archivo, nos recuerda Landa (2003), evita una taxonomía de esencialismos: funciona como contrapunto respecto a la clásica conceptualización de las totalidades orgánicas del tipo «el preso» o «el guardián», implica cierta autonomía de los términos, evita las reificaciones a favor de mostrar lógicas de funcionamiento y, en fin, identifica las singularidades.

\section{Norma y conflicto}

La singularidad normalizada, la diferenciación individualizante no solo se consiguen a través de esta utilización del archivo, sino también a partir de la imposición del valor normativo como un concepto propiamente político. El origen de esta indagación lo encuentra Foucault en las investigaciones de Canguilhem (1966), en concreto en las nuevas reflexiones relativas a lo normal y lo patológico, donde este se ocupa de las normas con relación a lo social. Reconoce la fecundidad que allí se encuentra con relación a la norma y sus principios en tanto en cuanto indican un proceso general de normalización social, política y técnica que comienza a desarrollarse ya en el siglo xviII, y cuyos efectos se observan en distintas instituciones (escuela, hospital, fábrica). Además, destaca la idea de que la norma no se define como una ley natural, sino por la presión que puede ejercer en el ámbito donde se la aplica. En este sentido, la norma:

No es simplemente, y ni siquiera un principio de inteligibilidad; es un elemento a partir del cual puede fundarse y legitimarse cierto ejercicio del poder. Concepto polémico, dice Canguilhem. Tal vez podría decirse político. (...) 
la norma trae aparejados a la vez un principio de calificación y un principio de corrección. Su función no es excluir, rechazar. Al contrario, siempre está ligada a una técnica positiva de intervención y transformación, a una especie de proyecto normativo. (Foucault, 2001: 57)

En efecto, la norma posee un carácter inmanente, carece de necesidad y no puede depender de ella misma; no es exterior a sus formas fenoménicas en que aparece, que es el lugar donde se expresa como capacidad de regulación y ajuste, pero cada una de ellas tampoco constituye la encarnación perfecta del valor normativo. Es solamente una preferencia que ha obtenido, en un territorio en disputa, el privilegio de asumir su papel como ajuste dominante. Lo que vemos en este sentido es un desplazamiento en la consideración de la norma como concepto polémico a la de la norma como concepto propiamente político, lo cual se halla en consonancia con la concepción que tiene sobre la política como conflicto, entre lo normal y lo patológico, entre lo normal y lo anormal.

El anormal, objeto de preocupación desde fines del siglo xix de instituciones, discursos y saberes, deriva de la excepción jurídico-natural del monstruo, de los numerosos incorregibles y de la inquietante sexualidad del niño masturbador. Si bien, señala Foucault, esas figuras no van a confundirse, ya que pertenecen a distintos campos discursivos, convergerán en la figura del anormal, que será no solo objeto de saber, sino también de justificación social y moral de las tecnologías de poder enfrentadas a las abominaciones ante la ley divina y la de los hombres. Ante todo, la medicina y la justicia se estructurarán con relación a la presencia de los anormales y a la necesidad de defender a la sociedad de estos.

En última instancia, el principio de normalización no trata ni de expiar una culpa ni de reprimir, sino de referir las conductas del individuo a un conjunto comparativo, medir capacidades, diferenciar a los individuos, imponer una medida, trazar la frontera entre lo normal y lo anormal. Por ello la norma, la normalización, comienza a distinguirse del concepto jurídico de ley. La ley se propone diferenciar actos, distingue entre lo permitido y lo prohibido, y tiene su referencia en los códigos. La norma funciona de acuerdo con un sistema binario de gratificación y sanción; para ella, castigar es corregir. Mientras la ley separa y divide, la norma pretende homogeneizar?

Mientras que la taxonomía natural se sitúa sobre el eje que va del carácter a la categoría, la táctica disciplinaria se sitúa sobre el eje que une lo singular con lo múltiple. Permite a la vez la caracterización del individuo como individuo, y la ordenación de una multiplicidad dada. Es la condición primera para el control y el uso de un conjunto de elementos distintos: la base para una microfísica de un poder que se podría llamar celular. (Foucault, 1975a: 153)

9. Y lo hace para individualizar, localizar, clasificar individualidades. Tal es el carácter paradójico del poder normalizador, no tanto borrar las distinciones sino identificar las anomalías, establecer el seguimiento de las mismas, su corrección, etcétera. En suma, una normalización que establece diferenciaciones individualizantes y hace un saber de ello. 
Así, entre fines del siglo XVIII y comienzos del siglo xIX, las disciplinas «definirán un código que no será el de la ley sino el de la normalización, y se referirán necesariamente a un horizonte teórico que no será el del derecho, sino el campo de las ciencias humanas, y su jurisprudencia será la de un saber clínico» (ibid.). La norma corresponde a la aparición de un biopoder, es decir, de un poder sobre la vida y de las formas de gubernamentalidad ligadas a él. En otras palabras, el modelo jurídico de la sociedad elaborado entre los siglos XVII y XVIII cede su lugar a un modelo médico en sentido amplio, y se asiste al nacimiento de una verdadera «medicina social» que se ocupa de campos de intervención ampliados más allá del registro del enfermo y la enfermedad. Se trata de la introducción de un aparato de medicalización colectiva que maneja las «poblaciones» en virtud del establecimiento de mecanismos de administración médica, de control de la salud, la demografía, la higiene o la alimentación... Todo ello permite aplicar a la totalidad de la sociedad una distinción permanente entre lo normal y lo patológico e imponer un sistema de normalización de los comportamientos y las existencias, el trabajo y los afectos.

Así pues, la racionalidad punitiva es también lo que permite constatar, con cierto grado de certeza, el hecho de que «la ley funciona (cada vez) más como una norma» (Foucault, 1976: 174), entendiendo por esto la transformación suscitada en la práctica judicial en virtud de la invasión de ciertas tecnologías que no actúan al mismo nivel —ni califican ni reprimen el mismo tipo de conductas- que la ley soberana.

De todos modos, Mitchell Dean (1994: 154-157) sugiere que esta relación entre ley y norma obedece a un desplazamiento «teórico» mediante la crítica a las concepciones convencionales del poder basadas en el problema de la soberanía del Estado y que le enfrenta a las nociones del Estado concebido como una mera superestructura por parte del marxismo oficial de la época (década de los setenta) y hacerse eco de los movimientos antisistema, tanto en el ámbito de las democracias occidentales como en el de la oposición al socialismo de Estado (Dean y Villadsen, 2016: 18). Ya incluso en Vigilar y castigar (1975a), por ejemplo, Foucault insinúa que las disciplinas deberían considerarse infralegislativas o, mejor aún, antagonistas de la ley, en el sentido de que no se limitan a extender las formas definidas por las leyes en el nivel micro, sino que socavan los límites de la ley. En la medida en que la ley, el sistema jurídico y el Estado parecen ocupar el mismo plano en estos análisis iniciales de Foucault, este ejemplo indica los límites de la noción de disciplina como una suerte de infraestructura de la ley y el Estado. Pero en obras posteriores se desentiende de esta formulación, y el modo en que describe las relaciones entre la microfísica disciplinaria y los aspectos macro en el Estado aparece en términos de "codificación» de toda una serie de relaciones de poder que lo hacen posible, esto es, como un fenómeno de segundo orden, que presupone una agencia o una institución que organiza y reúne los elementos que funcionarán como un código. Es así como el Estado reúne, ordena y fija dentro de ese concierto «estratégico» las microrrelaciones de poder. 
Es una relación compleja, pues, la que existe entre la ley y la norma, y ni mucho menos cerrada. Dentro de los trabajos que analizan la relación entre el diagrama de poder y la ley en la obra de Foucault, una buena parte de las discusiones giran alrededor del carácter principal o secundario de la ley. La tesis de la expulsión sostiene que, dado el carácter represivo y prohibitivo de la ley, esta quedó relegada a un segundo lugar en un diagrama de poder que funciona en términos eminentemente productivos. A su vez, las distintas tesis de la inclusión han subrayado que la ley se inscribe en los dispositivos disciplinarios y en las tecnologías gubernamentales.

En este contexto, el trabajo de Ben Golder y Peter Fitzpatrick (2009) es innovador. Por un lado, porque desarrolla una lectura integral de la obra de Foucault y, por otro, porque trata de rescatar otro concepto de ley en Foucault, quien, si bien señaló que en las sociedades disciplinarias la ley se retiraba, en otros casos mostró la existencia de solapamientos de esta con diferentes tecnologías de poder (Golder y Fitzpatrick, 2009: 56-59). No obstante, cabe asumir que si la ley se mantiene como uno de los rasgos de la modernidad, esto implica preguntarse qué relación existe con las formas de poder. Las lecturas oscilan entre, o bien subordinar la ley a los dispositivos disciplinarios o mostrar que su lugar en el funcionamiento del poder es secundario; o bien resituar su papel dentro las tecnologías modernas de poder. En cualquier caso, bajo ninguna de estas perspectivas se advierte el doble plano que la ley adquiere en los escritos de Foucault: una ambivalencia entre «una ley subordinada y una ley superadora [surpassing], entre una ley que es confinada por la emergencia del poder disciplinario y el biopoder, y una ley que es ilimitada y siempre yendo más allá de sí misma y de aquello que quiere instrumentarla» (ibid., 39). Ambas dimensiones de la ley, en tanto en cuanto determinada y receptiva al exterior, no representan una contradicción, sino que «Foucault está, de hecho, afirmando algo enteramente consistente - y muy apropiado - sobre la ley» (ibid.). En otras palabras, el funcionamiento de la ley no se puede limitar a una mera herramienta del poder soberano ni a un instrumento del poder disciplinario; es «algo más», y es esto lo que Golder y Fitzpatrick pretenden desentrañar: este movimiento de la ley que es confinada pero también sobrepasa a aquello que la quiere confinar, es la «lógica identificable de la ley misma. Esta necesaria irresolución es constitutiva de la (des)unidad de la ley de Foucault» (ibid.: 53). Su carácter fijo y determinado, a la vez que ilimitado, constituye "dimensiones relacionadas de la misma ley» (ibid.). Si bien hay una dimensión de la ley que se relaciona con los mecanismos de poder, hay algo que la hace abrirse a ser de otro modo, y es esta la «irresolución que percibimos como constitutiva de la ley en Foucault [y ello] es, en sí mismo, una especie de resolución (de ahí irresolución)» (ibid.: 54). Los autores postulan una intensa correlación entre las disciplinas y la ley, a la vez que anuncian un carácter vacío de esta última. $\mathrm{Al}$ mismo tiempo, profundizan en la relación entre la ley y las relaciones de poder, pero también entre la ley y las prácticas de resistencia, paradigma en el cual enuncian que la ley constituye el lazo social de la modernidad. 
En Vigilar y castigar (1975a), Foucault tan solo considera la escisión entre ley - perteneciente al ámbito de la economía de poder basada en la soberanía- y norma — propia de la economía disciplinaria. Solo con posterioridad distinguirá entre a) ley o código, b) norma y reglamentos, y c) regulación o seguridad. De hecho, esta ausencia de los dispositivos securitarios le otorga a la cuestión de la medicalización indefinida un matiz normalizador, asunto que cambiará en Seguridad, territorio y población (2006) y Nacimiento de la biopolítica (2007a), donde la distinción entre normal y anormal deja de tener la importancia que tenía para los dispositivos disciplinarios; y por el contrario se abandona la estrategia de patologización de lo diferente por una estrategia de administración de los rangos diferenciales. Se trata de la lógica de la seguridad o de la regulación, y los problemas de la población y el territorio como ejes articuladores del biopoder.

La insistencia de Foucault en el principio normativo supone la quiebra del criterio universal de la ley, lo cual no significa su eliminación, sino su adaptación a la concurrencia de la singularidad y la multiplicidad. Frente a la idea según la cual la ley escinde limpiamente el dominio de lo legal frente a lo ilegal, la norma funcionará en el juego permanente que relaciona los ilegalismos con lo legal. Así va a ser el dispositivo carcelario: esas posibilidades de visibilidad y enunciabilidad, esas maquinarias punitivas que revelan el funcionamiento de las prácticas más allá de lo que se ve o se habla. No es que todo sea válido para la norma, pues Foucault busca un efecto de verdad, pero abierto a la contingencia del mundo y el pensamiento, y no a su unidad, pues es consciente de que no hay una verdad única (la ley), sino multiplicidad, y de que esto depende del régimen de verdad y saber. No obstante, cabe buscar aquí la complementariedad entre la ley y la norma no como elementos antitéticos, sino coadyuvantes y en permanente búsqueda de su propia eficacia.

\section{Gubernamentalidad: hacia la creación de un nuevo cuerpo social}

La gubernamentalidad, para Foucault, aparece primero como un análisis del Estado, no algo que está más allá del Estado ${ }^{10}$. Muestra las condiciones de una experiencia estatal como algo que se enfrenta a un ámbito externo, la sociedad civil, a la que debe conceder cierta libertad de acción para que el gobierno funcione, y surge de un diagnóstico del presente como un período en el que el Estado, incluso en el ejercicio de la propia autoridad que lo define, ha lle-

10. Como sugiere Dean (1994: 245), la gubernamentalidad es una noción paralela a la de Michael Mann (1988) sobre el poder infraestructural del Estado, o a la idea de Anthony Giddens (1985) sobre determinados lugares como "contenedores de poder», y a la concepción de Corrigan y Sayer (1985) sobre el papel del Estado en lo que llaman «regulación moral». Al igual que la gubernamentalidad, estas nociones son intentos de interrogar: primero, la dimensión técnico-administrativa del poder estatal; en segundo lugar, el funcionamiento del poder administrativo en el tiempo y el espacio; y, en tercer lugar, la relación entre las preocupaciones macrosociológicas de la formación del Estado y las preocupaciones microsociológicas de la individualidad, la identidad y la subjetividad. 
gado a ser considerado como esencialmente despótico, la fuente del mal en el mundo, y como una fuerza represiva que deforma nuestra subjetividad, tanto desde el interior como desde el exterior, y limita nuestra potencialidad en el mundo. Una noción, pues, que en gran medida corrige la dispersión analítica de la microfísica del poder disciplinario y la enfoca en una tecnología de poder estratégica. Así, en el curso Seguridad, territorio y población (2006) de 1977-78, Foucault se preguntaba:

Porque, después de todo, esas tecnologías generales de poder que se procuró reconstituir al margen de la institución, ¿̇no dependen en definitiva de una institución global, una institución totalizadora que es precisamente el Estado? ¿No sucede acaso que, al salir de esas instituciones locales, regionales y puntuales que son los hospitales, las prisiones, las familias, nos limitamos a encaminarnos hacia otra institución, de modo que solo nos apartaríamos del análisis institucional para ser conminados a entrar a otro tipo de análisis institucional u otro registro o nivel del análisis institucional, justamente aquel en que se trata del Estado? (...) Es muy posible extraer los mecanismos disciplinarios de los lugares donde se intenta ponerlos en juego, como las prisiones, los talleres, el ejército. Pero ¿̇no es el Estado el responsable, en última instancia, de su puesta en acción general y local? (Foucault, 2006: 144)

Pero sobre todo lo que nos interesa aquí consiste en cómo la gubernamentalidad acabará siendo el concepto clave para expresar estas racionalidades conformadas ${ }^{11}$. Por esta vía, la noción de gubernamentalidad se relaciona con la de biopolítica como tecnología de poder, que Foucault define como el acontecimiento decisivo de la modernidad, con procesos implicados de racionalización, como la estadística o los sistemas de información. Estas transformaciones implican el surgimiento de una nueva racionalidad de poder que añadir a las existentes. Incluso más adelante comprobará que en efecto no se trata de una, sino de varias racionalidades políticas incluidas en el problema, también de manera antagónica. Estos elementos conectan de un modo bastante directo con lo que Foucault analiza en el curso de 1978-1979 Nacimiento de la biopolítica (2007a) en relación con el problema de la racionalidad gubernamental, las democracias neoliberales y unas formas de poder que ya no serían las formas de la sociedad disciplinaria. Sin embargo, también hay elementos que enlazan este proceso más bien con aspectos de las sociedades disciplinarias como la lógica de lo normal y lo patológico que acabamos de revisar.

11. La gubernamentalidad da cuenta de un fenómeno propio y específico de la sociedad moderna: la configuración de la vida (pero también de la muerte) y cuyo epifenómeno central está constituido por la ecuación entre la animalidad y la politicidad, en el marco más general de la propuesta de análisis de la producción de la sociedad moderna como correlato del mercado. Así, la gubernamentalidad hace referencia a una relación muy particular entre la vida y el gobierno, mediante la cual aquella es modelada por el poder, sometida a él y, sobre todo, configurada de una cierta manera que impide toda otra posibilidad. Por tanto, saturación doble de lo real de este modo de vida no solo por su presencia, sino por la improbable existencia de otro modo. 
En efecto, las estrategias biopolíticas que podemos identificar por primera vez, en forma de rudimentos, durante el siglo XVIII, y que tienen como principal forma la medicina social, ya a comienzos del siglo XIX han modificado sus formas. En este caso, la medicina social se ve complementada con estrategias de control y regulación de la vida, cada vez más sofisticadas y que se relacionan con la creación de instituciones, procedimientos, saberes, técnicas y marcos jurídicos que pretenden la optimización, el cumplimiento de ciertos objetivos respecto de la población como objeto de intervención. La idea de «seguridad social» resulta interesante en esta dirección: lo que se busca es generar un sistema de regulación de la vida de la población, que trata de optimizar dicha vida, es decir, que no se debilite.

Ahora bien, creo que en todo eso hay una serie de cosas que son importantes. La primera sería la siguiente: la aparición de un elemento - iba a decir un personaje- nuevo, que en el fondo no conocen ni la teoría del derecho ni la práctica disciplinaria. La teoría del derecho, en el fondo, no conocía más que al individuo y la sociedad: el individuo contratante y el cuerpo social que se había constituido en virtud del contrato voluntario o implícito de los individuos. Las disciplinas, por su parte, tenían relación práctica con el individuo y su cuerpo. La nueva tecnología de poder no tiene que vérselas exactamente con la sociedad (o, en fin, con el cuerpo social tal como lo definen los juristas); tampoco con el individuo/cuerpo. Se trata de un nuevo cuerpo: cuerpo múltiple, cuerpo de muchas cabezas, si no infinito, al menos necesariamente innumerable. Es la idea de población. La biopolítica tiene que ver con la población, y ésta como problema político, como problema a la vez científico y político, como problema biológico y problema de poder, creo que aparece en ese momento. (Foucault, 2000: 222)

Este «nuevo cuerpo» se transformará en el problema político central. Si bien la metáfora del cuerpo social es antigua, encuentra un renovado frescor en las teorías políticas del siglo XvIII ${ }^{12}$. Como veíamos, el «cuerpo individual», como fuerza de trabajo o fuerza bélica, ha sido objeto también de las estrategias del poder, pero la aparición de este tercer cuerpo es la que resultará decisiva para la biopolítica, sobre todo por esa noción de lo múltiple o de la multiplicidad que expresa la formulación de Foucault. Si bien el cuerpo político cristalizado en la metáfora organicista tiende a presentar una idea de unidad y cohesión social, de identidad, entonces la sociedad se concibe como un todo organizado en torno a ciertos objetivos, un organismo que funciona en con-

12. Esposito (2006: 17) ha mostrado que esa frescura está todavía vigente durante el siglo xx. Si bien para Foucault el poder de normalización desea actualizar el ejercicio soberano que permitía dar muerte, debe hacerlo a través del racismo, que es la precondición para que el Estado se transforme en un agente de muerte; en cambio Esposito entiende que Foucault se mostró impreciso a la hora de conceptualizar las relaciones entre modernidad, biopolítica y totalitarismo, y las rupturas y continuidades entre el poder de soberanía y la biopolítica. Su apuesta teórica es mostrar que estas incertidumbres pueden resolverse si se emplea el paradigma de la inmunización, que permite mostrar el carácter exclusivamente moderno de la biopolítica. 
junto. Pero la multiplicidad del cuerpo social expresado en la idea de población constituye justamente el inverso de la metáfora organicista clásica o funcionalista; pues la población como cuerpo múltiple expresa la diversidad de intereses sociales y conflictos que constituyen la sociedad como conjunto. Cuando se afirma, entonces, que el centro de las estrategias biopolíticas lo constituye la población, se esclarece el componente de «normalización» que tales estrategias tienen sobre la vida de los sujetos.

No es una mera cuestión de vocabulario, sino que hay que prestar atención a un aspecto que suele tratarse secundariamente en los análisis sobre la biopolítica: las formas de racionalización del control de los sujetos se vuelven científicas. No solo desde la perspectiva de la medicalización, asunto que está claro, sino del saber científico en general en su relación con la planificación social de la vida biológica en su conjunto.

Esta tecnología de poder, esta biopolítica, va a introducir mecanismos que tienen una serie de funciones muy diferentes de las correspondientes a los mecanismos disciplinarios. En los mecanismos introducidos por la política, el interés estará en principio, desde luego, en las previsiones, las estimaciones estadísticas, las mediciones globales; se tratará, igualmente, no de modificar tal o cual fenómeno en particular, no a tal o cual individuo en tanto que lo es, sino, en esencia, de intervenir en el nivel de las determinaciones de esos fenómenos generales, esos fenómenos en lo que tienen de global. (Foucault, 2000: 223)

Estos fenómenos globales son los que diferencian fundamentalmente las estructuras de poder, pues ya no interesará el disciplinamiento de los individuos en cuanto tal, sino determinar de forma general la vida de estos. El poder de hacer vivir se plasma en este tipo de mecanismos reguladores de la mortalidad o de la asistencia social. La vieja metáfora según la cual los problemas sociales podían ser entendidos como enfermedades gira sobre su eje, y es ahora la enfermedad la que se vuelve un asunto público, asunto nosopolítico. Pero la enfermedad es solo una cuestión entre otras, lo que realmente interesa es la vida misma en su desarrollo. Es decir, la metáfora organicista se convierte en algo más: aquella vieja idea según la cual el Estado, o la sociedad, es semejante a un cuerpo se profundiza y corresponde a un «organicismo social», que sería $-\mathrm{y}$ en esto seguimos a Esposito- una reelaboración de la metáfora política del cuerpo. La semejanza ya no es solo analógica, el Estado o la sociedad conforman definitivamente un cuerpo en cuanto a sus funciones y necesidades, de modo que la funcionalidad política sería la de un organismo.

\section{La evolución de los sistemas punitivos y su carácter estratégico}

Otro aspecto fundamental que recoge la noción de racionalidad punitiva es la posibilidad de observar críticamente la evolución de los sistemas punitivos como un proceso relativamente independente del despliegue específico del fenómeno criminal. Se delinea así la posibilidad de un análisis histórico social 
de dichos sistemas capaz de desvelar el carácter ideológico de las legitimaciones que de vez en cuando se invocan desde una perspectiva institucional para imponer nuevos sistemas represivos del conflicto social y nuevos mecanismos de preservación de la hegemonía.

Como ya veníamos subrayando, las relaciones entre racionalidades y tecnologías, programas e instituciones son mucho más complejas que una simple aplicación o transferencia. La diferencia entre los objetivos previstos de un programa y sus efectos reales no se ciñe a la relación entre la pureza del programa y la impureza de la realidad, sino a las diferentes realidades y estrategias heterogéneas. La crítica que Foucault planteaba al abuso del concepto de ideología, como una planificación interesada y con aparente capacidad ilimitada de previsión, desemboca en su concepción de la historia no como el logro de un plan, sino lo que se encuentra "entre» esos niveles. Así, ve las racionalidades como parte de una realidad que se caracteriza por el permanente "fracaso» de los programas ${ }^{13}$. Al reconstruir esta «dimensión estratégica» también se deben tener en cuenta los conflictos y resistencias que se oponen a las tecnologías y racionalidades de gobierno. Las luchas y los enfrentamientos no solo tienen lugar en un intervalo entre los programas y su realización, tampoco se limitan a permanecer como una suerte de «energía negativa» o capacidad obstructiva. En lugar de «distorsionar» el programa "original», en realidad siempre forman parte de los propios programas y contribuyen activamente a formular «compromisos", "fisuras" e "incoherencias" dentro de ellos y, por tanto, a ayudar a su adaptación.

Este marco sigue dejando abierta la cuestión de cómo a partir de la disputa y de la relación compleja entre lo micro de las tecnologías y lo macro de la lógica gubernamental se forman estas facultades más generales. En esta codificación de las relaciones locales de poder es donde se hace posible introducir un término foucaultiano clave para el análisis de las racionalidades ya mencionado: la estrategia. La estrategia es la condición del ensamblaje de las diversas relaciones de poder en un código que permite captar la inteligibilidad de formas específicas y diversas de racionalidad, sus condiciones de surgimiento y existencia, y sus consecuencias para los atributos subjetivos, el comportamiento corporal y las formas éticas de vida adecuadas a las relaciones sociales particulares. Foucault utiliza el término estrategia de dos maneras: en primer lugar, para describir cómo la interconexión de los poderes múltiples, heteromorfos y dispersos llega a delinear las condiciones generales de dominación organizadas en una forma estratégica más o menos coherente y unitaria; en segundo lugar, para describir la acción global sobre estos poderes por cuanto busca dirigirlos hacia un objetivo unificado, o incluso global. Juntando estos

13. Un ejemplo que el propio Foucault proporcionó en Vigilar y castigar (1975a) es el fracaso del sistema penitenciario, que produjo la delincuencia como un efecto no deseado. En su genealogía de la prisión, hace caso omiso de las nociones de planificación intencional, tampoco enmarca el problema en términos de funcionalidad o adecuación, más bien la institucionalización de la prisión en el siglo XIx produjo la delincuencia como un efecto no planificado pero que acaba siendo adoptado. 
usos se puede decir que las estrategias surgen a la vez de los micropoderes y se hacen disponibles a partir de ellos, pero, una vez constituidos, estos son a su vez capaces de actuar sobre las múltiples relaciones para conformarlas en una "cadena o sistema». Por tanto, a partir de tales estrategias se da forma al «diseño general» del Estado en el ámbito penitenciario sobre el que pueden operar «las hegemonías sociales», es decir, la estructura de clases.

Semejante noción de estrategia, nos recuerda Dean (1994: 158 y ss.), podría considerarse un ejemplo de una de las proposiciones centrales de Foucault en relación con el poder: que este es a la vez intencional y no subjetivo, es decir, que, si bien tales estrategias globales son irreductibles a los deseos, intereses o voluntades de un grupo social o un individuo en particular, sin embargo, se articulan en torno a un nivel mínimo de racionalidad y cálculo. Este descubrimiento, y la afirmación de que esta racionalidad política tiene formas históricas definidas que están abiertas a la investigación histórica, conecta el pensamiento anterior de Foucault sobre el poder con su pensamiento posterior sobre el gobierno. También lo distingue de la sociología histórica del Estado que solo puede concebir la racionalidad del Estado en términos de los intereses de las clases y otras fuerzas o imputada por el analista a una forma de Estado específica. El problema de la estrategia nos lleva, pues, a la cuestión de la racionalidad y al problema general de la "voluntad de saber», o de las relaciones de "poder-saber». La noción de estrategia presupone que la acción política de las distintas agencias se basa en algún grado de cálculo, y esta racionalidad estratégica utiliza, pero no adopta, la forma de programas de gobierno y de acción explícitos, calculados y racionales. En otras palabras, la estrategia es racional en términos mínimos y no máximos. Como argumenta perspicazmente Colin Gordon:

la estrategia define la forma mínima de racionalidad del ejercicio del poder en general, que consiste en el conjunto móvil de operaciones por las que una multiplicidad de elementos heterogéneos (fuerzas, recursos, las características de un terreno, la disposición y relación de los objetos en el espacio-tiempo) son investidos de una funcionalidad particular relativa a un conjunto dinámico y variable de objetivos. (Gordon, 1980: 251)

En suma, la estrategia es el ensamblaje cínico, implícito y promiscuo de elementos heterogéneos. Una parte de los recursos de que dispone la estrategia son estos programas punitivos, los intentos planificados de hacer que lo real sea susceptible de ser gobernado y administrado, de hacerlo gobernable y administrable. La estrategia también presupone conjuntos de técnicas, inventos, medios materiales e intelectuales de gobierno, que podrían denominarse genéricamente tecnologías de poder y de gobierno. Sin embargo, la estrategia nunca es idéntica ni a la racionalidad política explícita del programa ni a las tecnologías, técnicas y prácticas gubernamentales de las que depende dicha racionalidad.

La transición estratégica de una penalidad teatral, sangrienta y dirigida al cuerpo del recluso revela el distinto carácter a partir de la hegemonía del modo de producción capitalista y del nuevo reconocimiento social del ser humano: 
el carácter de fuerza de trabajo utilizable en la valorización del capital. La noción misma de racionalidad punitiva trata de integrar elementos diversos más allá de lo atribuible a la mera dinámica económica, tal y como en cierto modo hizo el trabajo clásico de Rusche y Kirchheimer (1939). En otras palabras, se estudian procesos culturales más amplios y no menos influyentes que añadir a la dimensión económica para tratar de explicar cómo y por qué la reclusión se ha sedimentado históricamente en cuanto que práctica hegemónica de la penalidad.

Explicábamos antes cómo la racionalidad disciplinaria correspondía a un período histórico en el que la fuerza de trabajo transformada en trabajo asalariado debía insertarse en la organización productiva bajo el síntoma de la escasez de la fuerza de trabajo. Se trata de un momento político en que las intervenciones se realizan sobre lo social: políticas asistencialistas, sanitarias, educativas, y en el cual la redistribución y lucha contra la pobreza serán los principios rectores. Se consideran la criminalidad y en general la desviación como el resultado de una falta social y personal (deprivación relativa) que escapa a las responsabilidades exclusivamente individuales, y corresponde más bien a la colectividad alcanzar soluciones por medio del Estado y sus instituciones, así como mediante saberes expertos no solo propios del asistencialismo social, sino también médicos, psicológicos y psiquiátricos.

El tratamiento adecuado de los delincuentes requería medidas correctivas individualizadas, adaptadas cuidadosamente al caso específico o al problema particular, y no una tarifa penal uniforme aplicada mecánicamente. Se necesitaban conocimientos expertos, investigación científica e instrumentos de intervención flexibles, así como también una disposición a regular aspectos de la vida que el liberalismo clásico había considerado que debían estar fuera del alcance del gobierno. El sistema normativo del derecho tenía que ceder frente al sistema normalizador de la ciencia; el castigo tenía que ser reemplazado por el tratamiento. (Garland, 2001: 90)

Esa estrategia de regulación fordista comenzó a colapsar en Occidente a lo largo de la década de 1980, pues la nueva fuerza de trabajo fragmentada, diseminada y globalizada ha perdido mucho de su poder sobre las condiciones de trabajo: la «flexibilidad» tantas veces aducida no es en realidad sino un sinónimo de la pérdida del poder de contratación. La desregulación de los mercados, la deslocalización y la introducción masiva de nuevas tecnologías en el sistema productivo acabó por fragmentar y segmentar el trabajo (Fumagalli, 1997). Como consecuencia, una gran parte de la clase trabajadora ha sido expulsada de los sectores productivos reestructurados, para sumarse así a las crecientes masas de «desocupados», subocupados, trabajadores a tiempo parcial y trabajadores flexibilizados. Una fuerza de trabajo, pues, flexible, móvil y permanentemente en el límite entre inclusión y exclusión, trabajo y no trabajo, economía formal e informal, actividades legales e ilegales. A su paso surgirá toda una suerte de nuevas tecnologías de control y nuevas racionalidades de gobierno anunciadas por la transición desde un régimen de la escasez hacia un régimen excedentario. 
El acceso al salario, a la ciudadanía y a la integración está conectado a un requisito que está desapareciendo del horizonte. La vieja dicotomía en la que los pobres, los marginados y los excluidos eran a la vez «amenazas» $\mathrm{y}$ «recursos» para el desarrollo capitalista adopta un tono distinto, ya que cualquier «recurso» puede convertirse fácilmente en una "amenaza» para la estabilidad de todo el sistema (Adamson, 1984), lo que anuncia una crisis de la utopía disciplinaria.

Si el régimen de escasez puede ser definido como el universo en el que opera el «poder-saber», Giorgi (2002: 119-121) describe al régimen excedentario posfordista como el ámbito de emergencia de un poder caracterizado por su condición de no-saber: la fuerza de trabajo flexibilizada y en el límite entre la inclusión y la exclusión no se abre al conocimiento de los mecanismos de control y poder. Esta dificultad para distinguir entre «amenazas» $\mathrm{y}$ «recursos», clases «peligrosas» y «trabajadoras», «basura social» y "peligro social» (Box y Hale, 1986) obliga a las instituciones de control social a categorizar a sectores enteros de la fuerza de trabajo como "grupos de riesgo", y a implementar estrategias consecuentes de reclusión, incapacitación y vigilancia masivas. Son estrategias basadas en el riesgo, inspiradas en la seguridad e impulsadas en la probabilidad, que tienen por objetivo reducir la complejidad social. De ahí el surgimiento de las tecnologías de control basadas en tres prácticas específicas: vigilancia generalizada, acceso selectivo y reclusión masiva. No siempre estas prácticas implican la creación de nuevas instituciones de control; de hecho, el orden pospanóptico está a menudo caracterizado por la persistencia de las viejas instituciones (y especialmente la «institución panóptica» por excelencia: la prisión), cuya racionalidad, sin embargo, parece estar experimentando un proceso de transformación.

De esta manera, "comprender menos y castigar más" se convirtió en el nuevo sentido común. Ya no tenía ninguna relevancia atribuir a las condiciones y contextos sociales las causas de las conductas desviadas. La «incapacitación selectiva» representaba un paso importante hacia la nueva racionalidad penal de exclusión, cuyos efectos son más visibles en nuestros tiempos (Greenwood, 1982). De hecho, hablar de «incapacitación selectiva» implica, por un lado, teorizar explícitamente el abandono de cualquier ideal de rehabilitación y, por otro, ver el castigo únicamente como un instrumento para la separación física de la masa real o potencial de desviados de su contexto social más amplio. Lo que aquí resulta de interés es la lógica que subyace a esta perspectiva: la idea de que es posible seleccionar algunas categorías de personas que, siendo iguales en todo lo demás, debieran ser castigadas más severamente que otras debido a que presentan una serie de indicadores de propensión permanente al delito y que por ello se considera que no pueden ser reintegradas en la comunidad.

Interesa también concebir la correlación entre dichas técnicas punitivas y las formas de gubernamentalidad neoliberal que no solo se caracterizan por la intervención directa mediante aparatos estatales habilitados y especializados, sino que también desarrollan técnicas indirectas para dirigir y controlar a los individuos. La estrategia de responsabilizar a los sujetos individuales (y también a los colectivos, como las familias, las asociaciones, etcétera) supone tras- 
ladar la responsabilidad de los riesgos sociales como la enfermedad, el desempleo, la pobreza, etcétera, y de la vida en sociedad, al ámbito del que es responsable el individuo y transformarlo en un problema de «autocuidado». Una característica fundamental de la racionalidad neoliberal es la congruencia que trata de lograr entre un individuo responsable y moral y un individuo económico-racional. Aspira a construir sujetos responsables cuya calidad moral se basa en el hecho de que evalúan racionalmente los costos y beneficios de un determinado acto frente a otros actos alternativos. Dado que la elección de las opciones de acción es —o así lo tendría la noción neoliberal de racionalidadla expresión del libre albedrío sobre la base de una decisión autodeterminada, las consecuencias de la acción son soportadas por el sujeto, que también es el único responsable de ellas.

\section{Conclusión}

Hemos partido de una de las máximas de Foucault que posee una profunda raigambre nietzschiana (la fábula del conocimiento donde este se revela como ficción): una renuncia al "conocimiento» en sentido tradicional, así como el abandono de las posibilidades de la hermenéutica evitando el descubrimiento de «la verdad» única; es decir, una teoría de la perspectiva que es un sucedáneo de las teorías tradicionales, y que las supera en su crítica. No se trata de rastrear las condiciones de racionalidad que posibilitan las prácticas punitivas, sino de acudir a ellas mismas, a su «capilaridad», para desenmascarar las explicaciones racionales (jurídicas o científicas) que aparecen en sus manifestaciones.

Así constatamos no solo que la evolución de los sistemas punitivos resulta un proceso relativamente independente del despliegue específico del fenómeno criminal, sino que las relaciones entre racionalidades y tecnologías, programas e instituciones penales son mucho más complejas que una simple aplicación o transferencia. De esta forma, por ejemplo, se constata que disciplina y gubernamentalidad están estrechamente relacionadas. Ambas establecen racionalidades del castigo, y se sirven de técnicas, instituciones y saberes para su aplicación, sin que sea posible evaluar en qué medida una es más racional (o humanitaria) que otra. La primera es una tecnología para el gobierno del cuerpo, mientras que la segunda es una ciencia para el gobierno de una población en su propio territorio. Ambas racionalidades se basan en un saber económico destinado a aumentar la productividad social: las prácticas disciplinarias producen individuos que conformarán poblaciones productivas. Además, están unidas por una raigambre estratégica que ha permitido ensamblar las diversas relaciones de poder en un código que conecta lo micro y lo macro, las técnicas y el gobierno. Se parecen no solo porque responden de manera similar a problemas sociales paralelos, sino porque comparten el objetivo de transformar los cuerpos y organizarlos de manera productiva. Así, cuando aborda el fenómeno del panóptico, Foucault aclara la conexión entre la organización capitalista del trabajo y la distribución disciplinaria de los cuerpos, y revela la existencia de una lógica unitaria detrás de los diversos aparatos de la sociedad 
disciplinaria. Por su parte, la biopolítica es inmanente a la sociedad y crea relaciones y formas sociales a través de las formas colaborativas laborales (Vila, 2014: 82-83). Pero sobre todo produce y garantiza la seguridad de la sociedad, lo que incide en las nociones de riesgo y peligrosidad, que son conceptos que se van perfilando en los dispositivos disciplinarios.

\section{Referencias bibliográficas}

Adamson, Christopher (1984). «Toward a Marxist penology: Captive criminal populations as economic threats and resources». Social Problems, 31 (4), 435-458. $<$ https://doi.org/10.2307/800389>

Boullant, François (2003). Michel Foucault et les prisons. París: PUF.

Box, Steven y Hale, Chris (1986). «Unemployment, Crime and Imprisonment, and the Enduring Problem of Prison Overcrowding». En: Matthews Roger y Young Jock (eds.). Confronting Crime. Londres: SAGE, 72-99.

Canguilhem, Georges (1966). Lo normal y lo patológico. Buenos Aires: Siglo XXI (1971).

Corrigan, Phillip y Sayer, Derek (1985). The Great Arch: English State Formation as Cultural Revolution. Oxford: Basil Blackwell.

DeAn, Mitchell (1994). Critical and effective histories: Foucault's methods and historical sociology. Londres: Routledge.

Dean, Mitchell y VILladsen, Kaspar (2016). State phobia and civil society: the political legacy of Michel Foucault. Standford, CA: Standford University Press.

Esposito, Roberto (2006). Bíos. Biopolitica y filosofia. Buenos Aires: Amorrortu.

Ewald, François (1990). «Un poder sin afuera». En: Deleuze, Gilles et al. (eds.). Michel Foucault, filósofo. Barcelona: Gedisa, 164-169.

Foucault, Michel (1969). La arqueología del saber. México: Siglo XXI (2003).

- (1973). La verdad y las formas jurídicas. Barcelona: Gedisa (1998).

- (1975a). Vigilar y castigar. Nacimiento de la prisión. Madrid: Siglo XxI (1976).

- (1975b). «La prison vue par un philosophe français». Dits et écrits II. 19701975, 725-731. París: Gallimard.

- (1976). La historia de la sexualidad I. La voluntad de saber. Madrid: Siglo XXI. (1998).

- (1991). "Questions of method». En: Burchell, G.; Gordon, C. y Miller, P. (ed.). The Foucault effect: Studies in governmentalit. Hemel Hempstead: Harvester Wheatsheaf, 73-86.

- (2000). Defender la sociedad. Curso en el Collège de France (1975-1976). México: Fondo de Cultura Económica.

- (2001). Los anormales. Curso en el Collège de France (1974-1975). Buenos Aires: Fondo de Cultura Económica.

- (2006). Seguridad, territorio y población. Curso en el Collège de France (1977-1878). Buenos Aires: Fondo de Cultura Económica. 
- (2007a). Nacimiento de la biopolítica. Curso en el Collège de France (19781979). Buenos Aires: Fondo de Cultura Económica.

- (2007b). El poder psiquiátrico. Curso en el Collège de France (1973-1974). México: Fondo de Cultura Económica.

- (2018). La sociedad punitiva. Curso en el Collège de France (1972-1973). Buenos Aires: Fondo de Cultura Económica.

Fumagalli, Andrea (1997). "Aspetti dell'accumulazione flessibile in Italia». En: Bologna, Sergio y Fumagalli, Andrea (eds.). Il lavoro autonomo di seconda generazione. Scenari del postfordismo in Italia. Milán: Feltrinelli, 133-169.

Garland, David (1990). Castigo y sociedad moderna. Un estudio de teoría social. Madrid: Siglo XXI (1999).

- (2001). Cultura del control. Crimen y orden social en la sociedad contemporánea. Barcelona: Gedisa (2005).

Giddens, Anthony (1985). The Nation-State and Violence. Cambridge: Polity. Giorgi, Alessandro de (2002). El gobierno de la excedencia. Postfordismo y control de la multitud. Madrid: Traficantes de Sueños (2006).

- (2007). «Toward a political economy of post-Fordist punishment». Critical Criminology, 15 (3), 243-265. <https://doi.org/10.1007/s10612-007-9029-1>

Golder, Ben y FitzPatrick, Peter (2009). Foucault's Law. Londres: Routledge. Gordon, Collin (1980). «Afterword». En: Collin, Gordon (ed.). Michel Foucault. Power/Knowledge: Selected Interviews and Other Writings 19721977. Brighton: Harvester.

Greenwood, Peter W. (1982). Selective incapacitation. Santa Monica: Rand Corporation.

Ignatieff, Michael (1978). A Just Measure of Pain: The Penitentiary in the Industrial Revolution, 1750-1850. Nueva York: Pantheon Books.

Lascoumes, Pierre (2007). "Surveiller et punir. Laboratoire de la problématique de la gouvernementalité: des technologies de surveillance pénitentiaire à l'instrumentation du pouvoir». En: CicCHInI, M. y Porret, M. (eds.). Les sphères du penal avec Michel Foucault. Histoire et sociologie du droit de punir. Lausana: Antipodes, 19-32.

LaNDA, Manuel de (2003). «The archive before and after Foucault». En: Brouwer, J.; Mulder, A. y Charlton. S. (eds.). Information is Alive, Art and Theory on Archiving and Retrieving Data, 2. Rotterdam: Publishing/NAI Publishers.

Legrand, Stéphane (2007). Les normes chez Foucault. París: PUF.

Legrand, Stéphane y Keck, Frédéric (2003). «Les épreuves de la psychiatrie» En: Blanc, G. Le y Terrel, J. (dir.). Foucault au Collège de France. Burdeos: Presses Universitaires de Bordeaux.

Machado, Roberto (1999). "Arqueología y epistemología». En: VV. AA. Michel Foucault, filósofo. Barcelona: Gedisa.

Mann, Michael (1988). States, War and Capitalism: Studies in Political Sociology. Oxford: Basil Blackwell. 
Panier, Christian y Watte, Pierre (2012). «El intelectual y los poderes. Entrevista con Michel Foucault (1981)». En: Foucault, Michel. El poder es una bestia magnifica. Sobre el poder, la prisión y la vida. Buenos Aires: Siglo XXI, 159-165.

Pashukanis, Evgeni B. (1927). Teoría general del derecho y el marxismo. Barcelona: Labor (1976).

Passeron, Jean-Claude (1991). Le raisonnement sociologique. L'espace nonpoppérien du raisonnement naturel. París: Nathan.

Pavarini, Massimo y Melossi, Dario (1977). Cárcel y fábrica. Los orígenes del sistema penitenciario (siglos XVI-XIX). México: Siglo XXI (1980).

Rusche, George y Kirchheimer, Otto (1939). Pena y estructura social. Bogotá: Editorial Temis (2004).

VILA VIÑas, David (2014). La gobernabilidad más allá de Foucault. Un marco para la teoría social y política contemporáneas. Zaragoza: Prensas de la Universidad de Zaragoza.

Mario Domínguez Sánchez-Pinilla es licenciado en Geografía e Historia, Ciencias Políticas y Sociología. Doctor en Sociología y Máster en Investigación Social. Profesor titular de universidad en la Facultad de Ciencias Políticas y Sociología, Departamento de Sociología: Metodología y Teoría, especializado y docente en teoría sociológica y sociología del conocimiento.

Mario Domínguez Sánchez-Pinilla has degrees in Geography and History, Political Science and Sociology. He has a Master's in Social research and a PhD in Sociology. He is an associate professor at the Faculty of Political Science and Sociology, in the department of Sociology: Methodology and Theory, specialising in and teaching sociological theory and sociology of knowledge.

David J. Domínguez González es licenciado en Filosofía por la Universidad de Deusto y Doctor Europeo en Sociología por la Universidad Complutense de Madrid. Profesor ayudante de la Facultad de Ciencias Políticas y Sociología, Departamento de Sociología: Metodología y Teoría, especializado y docente en criminología y epistemología de las ciencias sociales.

David J. Domínguez González has a degree in Philosophy from the University of Deusto and a European $\mathrm{PhD}$ in Sociology from the Complutense University of Madrid. He is a teaching assistant at the Faculty of Political Science and Sociology, Department of Sociology: Methodology and Theory, specialising in and teaching criminology and epistemology of the social sciences. 